\title{
Citrulline: from metabolism to therapeutic use
}

\section{Running title: citrulline: metabolism and therapeutic}

Senda Bahri Hicheri ${ }^{1,2}$, PhD; Naima Zerrouk ${ }^{2}$, PhD; Christian Aussel ${ }^{3}$, PharmD, PhD;

Christophe Moinard ${ }^{3}$, PhD; Pascal Crenn ${ }^{4}$, MD, PhD; Emmanuel Curis ${ }^{5}$, PhD; Jean-

Claude Chaumeil ${ }^{2}$, PharmD, PhD; Luc Cynober ${ }^{3}$, PharmD, PhD; Souad Sfar ${ }^{1}$, PhD.

${ }^{\mathbf{1}}$ Laboratoire de pharmacie galénique, Faculté de pharmacie. Monastir, Tunisie.

${ }^{2}$ Laboratoire de pharmacie galénique-Faculté de pharmacie Université Paris Descartes. Paris, France.

${ }^{3}$ Laboratoire de biologie de la nutrition, EA 4466, Faculté de pharmacie Université Paris Descartes. Paris, France

${ }^{4}$ EA 4497, Université Versailles Saint Quentin en Yvelines, Hôpital Raymond Poincaré (APHP), Garches, France.

${ }^{5}$ Laboratoire de biomathématiques-Faculté de pharmacie Université Paris Descartes. Paris, France

${ }^{6}$ Service de Biochimie interhospitalier Cochin Hôtel Dieu, AP-HP, Paris, France

\section{Statement of authorship}

S Bahri Hicheri wrote the manuscript. All the other authors read and corrected the manuscript.

Word count: 5047

Number of figures and tables: 1 figure, 2 tables

Correspondence: Dr Senda BAHRI HICHERI

Laboratoire de pharmacie galénique, Faculté de pharmacie de Monastir, Rue Avicenne. 5000. Monastir, Tunisie.

e-mail : sendabahri@hotmail.com 


\begin{abstract}
Citrulline displays a highly specific metabolism. Citrulline bypasses the splanchnic extraction; it is neither used by the intestine nor taken up by the liver. Thus the administration of citrulline may be utilized to deliver nitrogen making it available for the protein homeostasis in peripheral tissue and as an arginine precursor synthesized de novo in the kidneys, in endothelial and immune cells. A recent work showed that citrulline is efficiently transported across the intestinal luminal membrane, using a set of transporters belonging to systems $\mathrm{B}^{0,+}$, $\mathrm{L}, \mathrm{b}^{0,+}$. Several pharmacokinetic studies confirm that citrulline is efficiently absorbed when orally administered. Oral citrulline could be used either as a method to deliver arginine to the systemic circulation or as a protein anabolic agent in specific clinical situations: recent data suggest that citrulline, while not a component of proteins, stimulates protein synthesis in skeletal muscle through the mTOR signalling pathway. Hence, citrulline could play a pivotal role in maintaining protein homeostasis and is a promising pharmaconutrient in nutritional strategies in malnourished patients, especially in aging and sarcopenia.
\end{abstract}

Key words: citrulline, metabolism, transport, pharmacokinetics, arginine 


\section{Introduction}

Citrulline was firstly identified and isolated from the juice of watermelon, Citrullus vulgaris (1). This amino acid attracted relatively little interest until recently because it is a non protein amino acid and considered solely as an intermediate metabolite in ureagenesis $(2,3)$. However, in the last decade interest about citrulline has risen substantially because of its very specific metabolism.

Since citrulline is almost exclusively synthesized by the intestine, plasma citrulline has been identified as a biomarker of functional small bowel enterocyte mass (for recent reviews see 4, 5). In addition, as kidney is the main organ that metabolizes citrulline into arginine, renal failure is associated with an impairment of citrulline metabolism. The increase in plasma citrulline has been reported to be a potential marker of renal function (6). These features highlight the major role of intestine and kidneys in citrulline production and disposal respectively.

As it is a precursor of arginine, citrulline is also being investigated as a supplement from which arginine can be synthesized. In addition, arginine can be recycled from citrulline in some cells and this is of major importance in the so-called nitric oxide (NO) cycle. Hence citrulline can act as an arginine precursor for NO synthesis (7) and plays an important role in the metabolism and regulation of NO (8). Therefore, its administration may constitute a therapeutic strategy for controlling NO metabolism disorders and improving cardiovascular function. Citrulline supplementation should be considered for use in all circumstances or disease states in which arginine has beneficial effects and/or where arginine supplementation may be considered as harmful (9). Moreover, aging is associated with high splanchnic sequestration of amino acids and sarcopenia (10). Citrulline escapes splanchnic extraction and can stimulate muscle protein synthesis (11). Thus administering citrulline is a tool to deliver adequate amounts of nitrogen to peripheral tissues, including the muscle, in elderly. 
Therefore, citrulline administration has potential beneficial effects in different situations. In this review paper, we report experimental data of pharmacokinetic studies and clinical trials involving oral administration of citrulline as an alternative to arginine. As citrulline bioavailability is dependent on its intestinal absorption and amino acid transport systems may regulate substrate availability for citrulline-requiring enzymes in the intestine, a brief description of citrulline amino acid transport systems will be done.

\section{Metabolism of citrulline}

\subsection{Citrulline transport studies in intestinal models}

In the rat intestine, citrulline absorption seems to be optimal between the median and lower ileum (12). In addition, there is no evidence for an increased or decreased uptake of Lcitrulline by enterocytes under low or high protein or L-citrulline intake (8).

While citrulline transport in several cell types is well characterised (Table 1), currently transport mechanism of L-citrulline in the intestine is poorly documented. There are only two reports describing a concentration gradient transport across the everted sacs of the rat intestine (13) and an active transport by a neutral amino acid transport system in the hamster intestine (14). It was also showed in everted sacs of the small intestine that citrulline transport is mediated by a carrier-mediated active transport (12). Competition studies revealed the implication of NBB system. This system corresponds to the system $\mathrm{B}^{0}(15)$. L-citrulline could also be transported by a system analogous to system ASC (12).

In Caco-2 cells, a model for intestinal uptake studies, we have characterized kinetics of citrulline uptake (16). At the apical side, citrulline uptake involved a $\mathrm{Na}^{+}$- dependent transporter (System $\mathrm{B}^{0,+}$ ) and a $\mathrm{Na}^{+}$- independent saturable transport including systems $\mathrm{L}$ and 
$\mathrm{b}^{0,+}$ and no saturable diffusion. These transport systems take up citrulline from the lumen with comparable activities (table 1). It can be hypothesized that this large spectrum of transport systems compensates for the low content of citrulline in food, which may be important given the key role of citrulline in arginine de novo synthesis (16).

Citrulline transport has also been characterized in several other cell types: macrophages (17), rat aortic smooth muscle cells (18), neural cell cultures (19) and bovine aortic endothelial cells (20) (Table 1).

\subsection{Intestinal metabolism of citrulline}

Intestinal citrulline production originates mainly from the proximal small bowel and probably from the middle and upper parts of intestinal villi (4).

Glutamine is generally considered as the major precursor of citrulline in the intestine (7). Citrulline is one of the end products of glutamine metabolism accounting for $27.6 \%$ of metabolized glutamine (21). The synthesis of citrulline from glutamine involves five mitochondrial enzymes: phosphate-dependent glutaminase (PDG), pyrroline-5-carboxylate synthase (P5CS), ornithine aminotransferase (OAT), OCT (ornithine carbamoyltransferase) and CPSI (carbamoyl phosphate synthetase I) (22). Key regulation enzymes are OAT and P5CS which are unique to small intestinal enterocytes (23). This metabolic pathway is summarized in figure 1.

Besides, glutamine and some other amino acids can contribute to the intestinal production of citrulline. Indeed, citrulline can be synthesized from arginine because enterocytes possess the enzyme arginase which transforms arginine into ornithine (24). Ornithine is then converted into citrulline via OCT. Whether glutamine or arginine is the major precursor of citrulline is now controversial $(25,26)$. 


\subsection{Whole body inter-organ exchanges and catabolism}

Following release from enterocyte, citrulline passes through the liver without major metabolism and reaches the systemic circulation. The liver does not contribute significantly to circulating citrulline levels (21). Human liver might be capable of taking up a substantial amount of intestinal derived citrulline and thus limiting the amount of citrulline reaching the kidney (27). However in that study, the subjects were studied per-operatively for cancer. It cannot be excluded that liver bearing cancer expresses citrulline transporters which do not exist in normal liver.

The kidney is the major consumer of circulating citrulline. It takes up about $1.5 \mathrm{~g}$ citrulline per day from the blood (28). Approximately $83 \%$ of the citrulline released by the gut is metabolized within the kidney, and this represents $35 \%$ of circulating citrulline (21). $75 \%$ of the citrulline extracted from the blood is converted stochiometrically into arginine through a partial urea cycle by argininosuccinate synthetase (ASS) and argininosuccinate lyase (ASL) (23, 29). Synthesized arginine is released into the renal vein and then to systemic blood circulation (28). Citrulline converted by the kidney is enough to sustain whole body arginine requirements. Arginine synthesized from citrulline represents $60 \%$ of the de novo arginine synthesis in the organism, but only 5 to $15 \%$ of circulating arginine (30).

\section{Pharmacokinetics of citrulline}

Mandel et al. (1) studied the response of plasma citrulline and arginine to ingestion of watermelon in healthy volunteers. A one-time intake of watermelon increased plasma concentrations of citrulline and arginine when measured immediately after ingestion (Table 2) and then declined to baseline concentrations at $8 \mathrm{~h}$ post watermelon ingestion. The study is limited by uncertainty as to the actual amount of citrulline ingested, but the mean citrulline intake was likely around $7 \mathrm{~g}$. Collins et al.(31) investigated whether watermelon juice 
consumption increases fasting concentrations of plasma arginine, ornithine and citrulline in healthy humans. In contrast to Mandel et al. (1), they used long-term feeding with watermelon (31). Three weeks of daily ingestion of 6 cups of watermelon juice elevated plasma arginine and ornithine concentrations (table 2). No significant changes in fasting plasma citrulline were found. This is due to the high turnover rate of arginine and citrulline.

In conclusion, dietary supplementation with citrulline is an effective alternative to oral administration of arginine. Hence watermelon may have important implications for preventing and treating diseases involving arginine deficiency (31). However, the use of large volume of watermelon juice raises the question of good compliance in the context of long term feeding. In healthy volunteers, Moinard et al. (32) performed a dose-ranging study of citrulline oral administration. After citrulline load, plasma citrulline and arginine concentrations increased proportionally to citrulline load rapidly and massively and returned to baseline after 5-8 h. However, at the highest dose (15 g), arginine production was not related to the dose administered, suggesting that citrulline to arginine conversion in the kidney may be limiting and that saturation begins to occur at around this dose of citrulline. Therefore, Moinard et $a l$. (32) suggest that a $10 \mathrm{~g}$ dose should be the most appropriate for use in clinical practice. Plasma concentrations of amino acids other than ornithine and arginine are not affected by citrulline supplementation $(31,32)$. This means that citrulline is a compartmentalized amino acid performing a specific job in terms of arginine metabolism (32).

Rougé et al. (33) also found that oral administration of citrulline can be used to enhance systemic citrulline and arginine availability and nitrogen balance. Citrulline is highly bioavailable, since systemic citrulline rose dramatically whereas urinary citrulline loss was minimal $(32,33)$.

Moreover, Kuhn et al. (34) observed that oral citrulline is more effective than arginine itself in elevating circulating arginine levels (table 2) and speculate that it may be more effective in 
raising nitric oxide levels in patients with pulmonary hypertension. This observation is confirmed by the study of Schwedhelm et al. (35). Pharmacokinetic parameters were calculated after 1 week of oral supplementation of six different dosing regimens of placebo, citrulline and arginine (Table 2). Oral citrulline supplementation raised plasma arginine concentration and increased NO-dependent signalling in a dose dependent manner. Besides, at the dose of $3 \mathrm{~g}$, citrulline was more efficient in increasing $\mathrm{C}_{\max }, \mathrm{C}_{\min }$ and $\mathrm{AUC}$ over baseline placebo than arginine itself.

A recent study (36) compared the pharmacokinetics of citrulline, arginine and glutamine supplied orally, in catabolic conditions in rats. Endotoxemia considerably decreased citrulline bioavailability, whereas it did not affect arginine and glutamine pharmacokinetics. These results could have important clinical implications. However, if the target of citrulline supplementation is to use it as an arginine precursor, citrulline remained a better arginine precursor than arginine itself in this pathological condition (36). However, if the target is the specific anabolic properties of citrulline (see below), it may certainly be better to provide citrulline by the parenteral route.

Finally, the rapid disappearance of citrulline from the blood may be a disadvantage if we consider that high citrulline plasma level may trigger its action. For this purpose, galenic formulations have been established to sustain its plasma level (37).

\section{Perspectives for therapeutic use of citrulline}

\subsection{In malnutrition state}

\subsubsection{Malnutrition associated to intestinal failure}

Citrulline is lowered after a large intestinal resection leading to intestinal failure (38), in villous atrophy (39) or in HIV enteropathy (40). Recent papers discuss the interest of citrulline concentration as an indicator of acute intestinal failure in critically ill patients (41) 
or as marker of bowel adaptation in children with short bowel syndrome (42). Since citrulline and subsequently arginine concentrations are decreased in these situations, arginine supplementation seems logical, arginine becoming essential (43). Nevertheless, arginine undergoes significant liver uptake and its metabolism (e.g. into NO) raises concerns over whether arginine supplementation may potentially be unsafe (9). Last but not least, arginine is relatively badly absorbed by the intestine, leading to intestinal discomfort and diarrhea when given at high dosage (44). Conversely, citrulline has very high bioavailability (45).

In experimental intestinal resection, one study has supplemented citrulline instead of arginine by enteral route (43) whereas a second study used citrulline by parenteral route (46). In the first study, rats were assigned to four groups: citrulline, arginine, controls and shams. The latter underwent transection while the three other groups underwent $80 \%$ resection of the small intestine. Plasma and muscle arginine concentrations were higher in the citrulline group than in the other groups. Nitrogen balance was preserved in citrulline-treated resected rats but not in arginine-supplemented rats. In the parenteral study (46), rats were assigned to four groups as in the previous study. Both citrulline and arginine increased mucosal protein content in the ileum. However, only citrulline prevented extensor digitorum longus atrophy. In addition, arginine worsened nitrogen balance whereas citrulline was unable to improve it, in contrast with enteral citrulline supplementation (43). Only citrulline was able to prevent muscle atrophy. This was achieved independently of any noticeable effect on the gut, since citrulline and arginine shared the same positive effect on mucosal ileal protein content. To date there is no data on the potential effects of citrulline on intestinal adaptation.

\subsubsection{Aging and sarcopenia}

Aging is associated with a progressive loss of muscle mass and function (47). In elderly, sarcopenia is associated to a reduced post prandial rate of muscle protein synthesis (48). This 
may be due to a higher splanchnic extraction in the elderly (49) which implies that fewer amino acids reach the systemic circulation (50). Increasing the overall availability of amino acids can enhance protein synthesis in skeletal muscle by increasing the activities of positive regulators of translation initiation factors (47). Only one amino acid (i.e. leucine) was firmly proven to have a direct effect on muscle protein synthesis (51). This amino acid can activate several intracellular signals involved with initiating translation, the mammalian target of rapamycin (mTOR) signaling pathway, which includes 70-kda ribosomal protein S6 kinase (S6K1) and eukaryotic initiation factor 4E binding protein-1 (4E-BP1) (47). Recently it has been shown that dietary arginine supplementation increased mTOR signaling activity in skeletal muscle of neonatal pigs (52). The arginine treatment enhanced the formation of the active eIF4E'eIF4G complex and reduced the amount of the inactive 4E-BP1 eIF4E complex in muscle (52).

Citrulline supplementation led to increase in muscle protein content as well as muscle protein synthesis in elderly malnourished rats (11). It can directly stimulate protein synthesis particularly in the myofibrillar and sarcoplasmic protein synthesis (53). This amino acid activates the phosphorylation of proteins in the mTOR signaling pathway. Further study (54) using the same model support the idea that citrulline action is modulating protein synthesis through mTOR since this effect was counteracted when muscles were incubated in presence of rapamycin.

Recently, Faure et al. (55) demonstrated that muscle mass and motor activity significantly increased during refeeding of malnourished aged rats with citrulline. This study demonstrates the ability of citrulline to modulate muscle function. Of major interest, a recent study (56) indicates that orally administered citrulline increases muscle protein synthesis in healthy volunteers fed a hypoprotein diet, compared to isonitrogenous control. 


\subsection{Cardiovascular diseases}

In most studies, citrulline was investigated as a supplement from which arginine can be synthesized or as a NO precursor. In children undergoing surgical procedures for congenital heart lesions, oral citrulline supplements safely increased plasma citrulline and arginine concentrations compared with placebo and improved NO production (57). The arginine level was maintained in these patients, whereas it decreased in patients receiving the placebo. Increased plasma citrulline concentrations were associated with a decreased risk of postoperative pulmonary hypertension.

In sickle cell disease, citrulline had also a systemic vasodilator antihypertensive effect (58). Administered orally, citrulline improved cardiac performance with exercise and sense of wellbeing. It reduced total leukocyte counts and neutrophil counts (58).

\subsection{Safety issues}

Citrulline is generally recognized as safe for oral use (8). At the opposite of arginine or ornithine that induces gastrointestinal side effects at high dosage (i.e. $>10 \mathrm{~g}$ in one bolus) (44), citrulline is well tolerated $(31,32,35,57,58)$. This could be explained by rapid saturation of the intestinal absorption of arginine and ornithine which induce osmotic diarrhoea at high loads $(32,44)$. This difference between these amino acids suggests that intestinal absorption of citrulline is not a limiting step in citrulline bioavailability, even at high citrulline loads. 


\section{Conclusion}

The intestinal epithelium plays a central role in maintaining citrulline homeostasis by systemic providing citrulline. Citrulline is easily absorbed by the gut with a broad set of transporters that can carry it from the intestinal lumen in the enterocyte. This is confirmed by the result of pharmacokinetic studies. The major finding of these studies is that oral administration of L-citrulline efficiently increases L-arginine plasma concentrations. Moreover, giving citrulline is more efficient to provide systemic arginine than giving arginine itself, likely because it bypasses metabolism in the liver and it is not a substrate for arginase. Therefore, the use of citrulline as a pharmaconutrient is a promising treatment in diseases involving arginine deficiency. Another promising field of research for citrulline is its role in protein synthesis. 


\section{References}

1. Mandel H, Levy N, Izkovitch S, Korman S H. Elevated plasma citrulline and arginine due to consumption of Citrullus vulgaris (watermelon). J Inherit Metab Dis 2005;28:467-472.

2. Curis E, Nicolis I, Moinard C, Osowska S, Zerrouk N, Benazeth S et al. Almost all about citrulline in mammals. Amino Acids 2005;29:177-205.

3. Moinard C, Cynober L. Citrulline: a new player in the control of nitrogen homeostasis. J Nutr 2007;137:1621S-1625S.

4. Crenn P, Messing B, Cynober L. Citrulline as a biomarker of intestinal failure due to enterocyte mass reduction. Clin Nutr 2008;27:328-339.

5. Crenn P, Cynober L. Effect of intestinal resections on arginine metabolism: practical implications for nutrition support. Curr Opin Clin Nutr Metab Care 2010;13:65-69.

6. Lau T, Owen W, Yu Y M, Noviski N, Lyons J, Zurakowski D et al..Arginine, citrulline, and nitric oxide metabolism in end-stage renal disease patients. J Clin Invest 2000;105:1217-1225.

7. Wu G. Intestinal Mucosal Amino Acid catabolism. J Nutr 1998; 128:1249-52.

8. Romero M J, Platt D H, Caldwell R B, Caldwell R W. Therapeutic use of citrulline in cardiovascular disease. Cardiovasc Drug Rev 2006;24:275-290.

9. Heyland DK, Dhaliwal R, Drover JW, Gramlich L, Dodek P. Canadian clinical practice guidelines for nutrition support in mechanically ventilated, critically ill adult patients. JPEN 2003;27:355-373.

10. Fujita T, Yanaga K. Association between glutamine extraction and release of citrulline and glycine by the human small intestine. Life Sci 2007;80:1846-1850. 
11. Osowska S, Duchemann T, Walrand S, Paillard A, Boirie Y, Cynober L et al. Citrulline modulates muscle protein metabolism in old malnourished rats. Am J Physiol Endocrinol Metab 2006;291:E582-E586.

12. Vadgama J V, Evered D F. Characteristics of L-citrulline transport across rat small intestine in vitro. Pediatr Res 1992;32:472-478.

13. Evered D F, Nunn P B. Uptake of amino acids by mucosa of rat colon in vitro. Eur J Biochem 1968;4:301-304.

14. Lin E C, Hagihira H, Wilson T H. Specificity of the transport system for neutral amino acids in the hamster intestine. Am J Physiol 1962;202:919-925.

15. Barker G A, Ellory J C. The identification of neutral amino acid transport systems. Exp Physiol 1990;75:3-26.

16. Bahri S, Curis E, El Wafi FZ, Aussel C, Chaumeil JC, Cynober L et al.. Mechanisms and kinetic of citrulline uptake in a model of human intestinal epithelial cells. Clin Nutr 2008; 27:672-680

17. Baydoun A R, Bogle R G, Pearson J D, Mann G E. Discrimination between citrulline and arginine transport in activated murine macrophages: inefficient synthesis of NO from recycling of citrulline to arginine. Br J Pharmacol 1994; 112:487-492.

18. Wileman S M, Mann G E, Pearson J D, Baydoun A R. Role of L-citrulline transport in nitric oxide synthesis in rat aortic smooth muscle cells activated with LPS and interferon-gamma. Br J Pharmacol 2003;140:179-185.

19. Schmidlin A, Fischer S, Wiesinger H. Transport of L-citrulline in neural cell cultures. Dev Neurosci 2000;22:393-398. 
20. Hilderman R H, Casey T E, Pojoga L H. P(1),P(4)-Diadenosine 5'-tetraphosphate modulates 1-arginine and 1-citrulline uptake by bovine aortic endothelial cells. Arch Biochem Biophys 2000;375:124-130.

21. Windmueller H G, Spaeth A E. Source and fate of circulating citrulline. Am J Physiol 1981;241:E473-E480.

22. Lutgens L, Lambin P. Biomarkers for radiation-induced small bowel epithelial damage: an emerging role for plasma Citrulline. World J Gastroenterol 2007;13: 3033-3042.

23. Wu G, Morris S M, Jr. Arginine metabolism: nitric oxide and beyond. Biochem J 1998;336:1-17.

24. Cynober L, Le Boucher J, Vasson M P. Arginine metabolism in mammals. J Nutr Biochem 1995;6:402-413.

25. Marini JC, Didelija IC, Castillo L, Lee B. Glutamine: precursor or nitrogen donor for citrulline synthesis? Am J Physiol Endocrinol Metab 2010;299:E69-E79.

26. Ligthart-Melis GC, Vermeulen MA, van Leeuwen PA, Deutz NE. Glutamine: precursor or nitrogen donor for citrulline synthesis? Am J Physiol 2010;299:E683

27. Van de Poll M C, Ligthart-Melis G C, Boelens P G, Deutz N E, van Leeuwen P A, Dejong $\mathrm{C} \mathrm{H}$. Intestinal and hepatic metabolism of glutamine and citrulline in humans. J Physiol 2007; 581: 819-827.

28. Van de Poll M C, Soeters P B, Deutz N E, Fearon K C, Dejong C H. Renal metabolism of amino acids: Its role in interorgan amino acid exchange. Am J Clin Nutr 2004; 79: 185-197.

29. Levillain O. Expression and function of arginine-producing and consumingenzymes in the kidney. Amino acids. 2012; 42: 1237-1252. 
30. Morris SM, Jr. Arginine: beyond protein. Am J Clin Nutr 2006,83:508S-512S.

31. Collins J K, Wu G, Perkins-Veazie P, Spears K, Claypool P L, Baker R A, Clevidence B A. Watermelon consumption increases plasma arginine concentrations in adults. Nutrition 2007;23:261-266.

32. Moinard C, Nicolis I, Neveux N, Darquy S, Benazeth S, Cynober L. Dose-ranging effects of citrulline administration on plasma amino acids and hormonal patterns in healthy subjects: the Citrudose pharmacokinetic study. Br J Nutr 2007:1-8.

33. Rouge C, Des Robert C, Robins A, Le Bacquer O, Volteau C, De la Cochetiere M F. Manipulation of Citrulline Availability in Humans. Am J Physiol Gastrointest Liver Physiol 2007: 293:G1061-G1067.

34. Kuhn K P, Harris P A, Cunningham G R, Robbins I M, Summar M L, Christman B W. Oral citrulline effectively elevates plasma arginine levels for $24 \mathrm{~h}$ in normal volunteers. Circulation AHA Scientific Sessions 2006; abstract 1692:1339.

35. Schwedhelm E, Maas R, Freese R, Jung D, Lukacs Z, Jambrecina A, et al. Pharmacokinetic and pharmacodynamic properties of oral L-citrulline and Larginine: impact on nitric oxide metabolism. Br J Clin Pharmacol 2007:65:51- 59.

36. El Wafi FZ, Curis E, Zerrouk N, Neveux N, Chaumeil JC, Arnaud P, et al. Endotoxemia affects citrulline, arginine and glutamine bioavailability. Eur J Clin Invest 2012;42: 282-289.

37. Berthe MC, Darquy S, Breulliard C, Lamoudi L, Marc J, Cynober L, et al High plasma citrulline and arginine levels ensured by sustained-release citrulline supplementation. Nutrition 2011;27:1168-1171.

38. Crenn P, Coudray-Lucas C, Thuillier F, Cynober L, Messing B. Postabsorptive plasma citrulline concentration is a marker of absorptive enterocyte mass and intestinal failure in humans. Gastroenterology 2000;119:1496-1505. 
39. Crenn P, Vahedi K, Lavergne-Slove A, Cynober L, Matuchansky C, Messing B. Plasma citrulline: A marker of enterocyte mass in villous atrophy-associated small bowel disease. Gastroenterology 2003;124:1210-1219.

40. Crenn P, De Truchis P, Neveux N, Galperine T, Cynober L, Melchior JC. Plasma citrulline is a biomarker of enterocyte mass and an indicator of parenteral nutrition in HIV-infected patients. Am J Clin Nutr 2009;90:587-594.

41. Piton G, Manzon C, Cypriani B, Carbonnel F, Capellier G. Acute intestinal failure in critically ill patients: is plasma citrulline the right marker? Intensive Care Med. 2011;37:911-917.

42. Diamanti A, Panetta F, Gandullia P, Morini F, Noto C, Torre G, et al. Plasma citrulline as marker of bowel adaptation in children with short bowel syndrome Langenbecks Arch Surg. 2011;396:1041-1046.

43. Osowska S, Moinard C, Neveux N, Loi C, Cynober L. Citrulline increases arginine pools and restores nitrogen balance after massive intestinal resection. Gut 2004; $53: 1781-1786$.

44. Grimble G K. Adverse gastrointestinal effects of arginine and related amino acids. J Nutr 2007;137:1693S-1701S.

45. Cynober L. Pharmacokinetics of arginine and related amino acids. J Nutr 2007;137:1646S-1649S.

46. Osowska S, Neveux N, Nakib S, Lasserre V, Cynober L, Moinard C. Impairment of arginine metabolism in rats after massive intestinal resection: effect of parenteral nutrition supplemented with citrulline compared with arginine. Clin Sci 2008;115:159-166.

47. Fujita S, Volpi E. Amino acids and muscle loss with aging. J Nutr 2006;136:277S280S. 
48. Walrand S, Guillet C, Salles J, Cano N, Boirie Y. Physiopathological mechanism of sarcopenia. Clin Geriatr Med. 2011;27:365-385.

49. Boirie Y, Gachon P, Beaufre`re B. Splanchnic and whole-body leucine kinetics in young and elderly men. Am J Clin Nutr 1997;65:489-495.

50. Mosoni L, Valluy MC, Serrurier B, Prugnaud J, Obled C, Guezennec CY, et al. Altered response of protein synthesis to nutritional state and endurance training in old rats. Am J Physiol EndocrinolMetab 1995;268:E328-E335.

51. Li F, Yin Y, Tan B, Kong X, Wu G. Leucine nutrition in animals and humans: mTOR signaling and beyond.Amino Acids. 2011;41:1185-1193.

52. Yao K, Yin YL, Chu W, Liu Z, Deng D, Li T, et al. Dietary arginine supplementtaion increases mTOR signaling actvity in skeletal muscle of neonatal pigs. J Nutr 2008;138:867-872.

53. Moinard C, Jourdan M, Walrand S, Le Plenier S, Boirie Y, Cynober L. La citrulline exerce un effet direct sur la synthèse protéique musculaire. Nutr Clin Metabol 2007;21:S31-S32.

54. Le Plenier C, Walrand S, Cynober L, Moinard C. Direct action of citrulline on muscle protein synthesis: role of the MTORC1 pathway. Clin Nut suppl 2011;6:20.

55. Faure C, Raynaud-Simon A, Ferry A, Daugé V, Cynober L, Aussel C, et al. Leucine and citrulline modulate muscle function in malnourished aged rats. Amino Acids 2012; 42:1425-1433.

56. Jourdan M, Nair KS, Ford C, Shimke J, Ali B, Will B, et al. Citrulline stimulates muscle protein synthesis at the post-absorptive state in healthy subjects fed a lowprotein diet. Cli Nut Suppl 2008;3:11-12. 
57. Smith H A, Canter J A, Christian K G, Drinkwater D C, Scholl F G, et al. Nitric oxide precursors and congenital heart surgery: a randomized controlled trial of oral citrulline. J Thorac Cardiovasc Surg 2006;132:58-65.

58. Waugh W H, Daeschner C W, Files B A, McConnell M E, Strandjord S E. Oral citrulline as arginine precursor may be beneficial in sickle cell disease: early phase two results. J Natl Med Assoc 2001;93:363-371. 


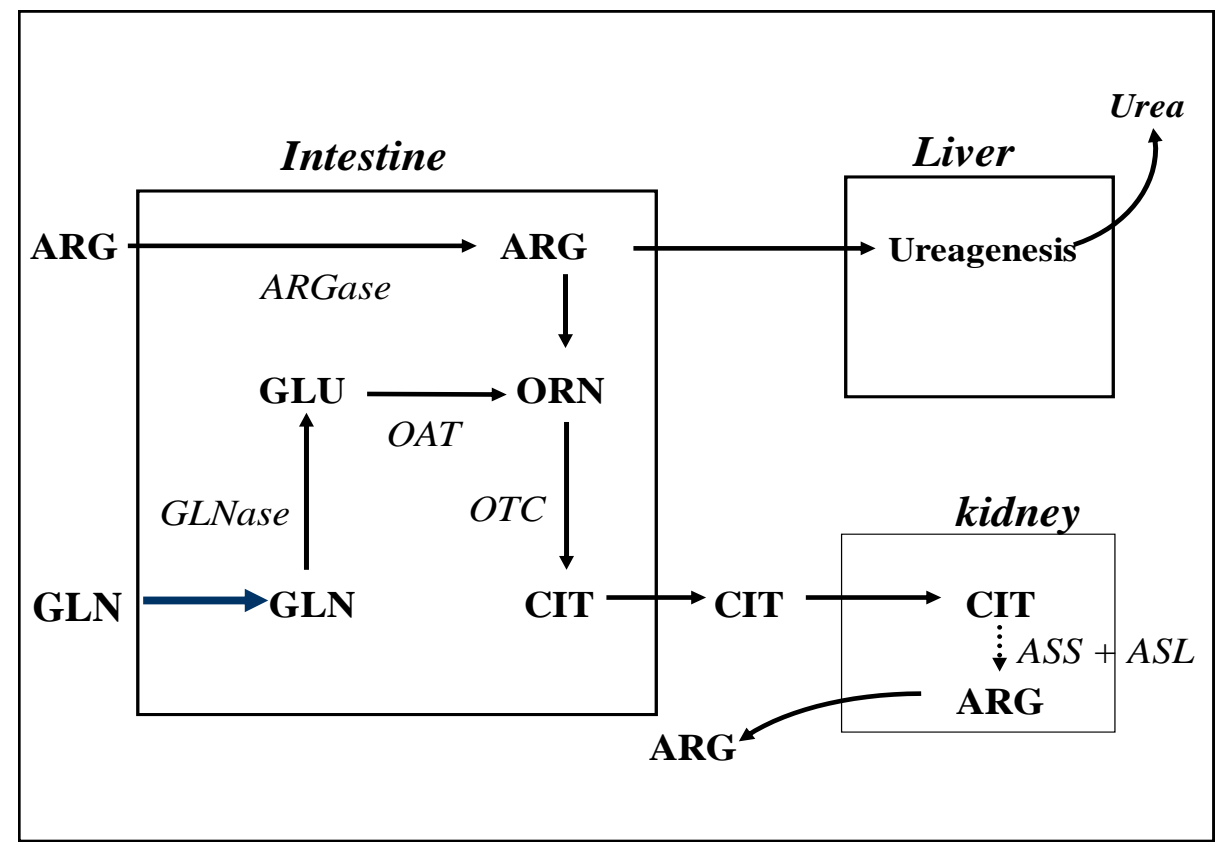

Figure 1: Interorgan metabolism of citrulline and related amino acids.

GLNase, Glutaminase; OAT, ornithine aminotransferase ; OCT, ornithine carbamoytransferase ; ARGase, arginase ; ARG, arginine; CIT, citrulline ; ORN, ornithine ;.GLN, glutamine; GLU, glutamate ; $A S S+A S L$, argininosuccinate synthetase + lyase Adapted from Crenn et al. (5). Reproduced with permission. 
Table 1: Characteristics of citrulline transport across cellular membranes

\begin{tabular}{|c|c|c|c|c|}
\hline Cell type & $\mathrm{K}_{\mathrm{m}}(\mathrm{mM})$ & $\mathrm{V}_{\max }\left(\mathrm{nmol} \cdot \mathrm{min}^{-1}\right)$ & Amino acid transport system & Reference \\
\hline \multirow{2}{*}{ Caco-2 Cells } & $0.46 \pm 0.07$ & $3.58 \pm 0.39$ & $\mathrm{~B}^{0,+}$ & \multirow{2}{*}{16} \\
\hline & $0.67 \pm 0.1$ & $2.16 \pm 0.23$ & $\mathrm{~L}$ and $\mathrm{b}^{0,+}$ & \\
\hline Rat intestinal everted sacs & $4.1 \pm 0.9$ & $0.62 \pm 0.06^{*}$ & $\mathrm{ASC}$ or $\mathrm{B}^{0}$ & 12 \\
\hline Aortic endothelial cell & & & Common transport system with arginine & 20 \\
\hline Aortic smooth muscle cell & $1.6 \pm 0.2$ & $5.9 \pm 0.6$ & $\mathrm{~L}$ and $\mathrm{N}$ & 18 \\
\hline Astroglial cell & $1.1 \pm 0.1$ & $14.7 \pm 0.9$ & \multirow{4}{*}{$\mathrm{L}$} & \multirow{4}{*}{19} \\
\hline Glial cells & $3.4 \pm 0.2$ & $25.6 \pm 1.4$ & & \\
\hline Microglial cell & $1.2 \pm 0.4$ & $31 \pm 0.2$ & & \\
\hline Macrophage & $0.4 \pm 0.1$ & $26.5 \pm 8.7$ & & \\
\hline Macrophage & $0.16 \pm 0.02$ & $32 \pm 1$ & Neutral AA transport system with a broad specificity & 17 \\
\hline
\end{tabular}

$\mathrm{V}_{\max }$ values are for $1 \mathrm{mg}$ of protein, except when marked with a star where values are for $1 \mathrm{mg}$ of wet tissue 
Table 2: Pharmacokinetic studies of citrulline

\begin{tabular}{|c|c|c|c|c|}
\hline Study & Patients & Dosage $^{1}$ & Plasma concentration achieved, $\mu \mathrm{mol} / \mathrm{l}$ & Reference \\
\hline Randomized study & 10 healthy volunteers & $0.18 \mathrm{~g} / \mathrm{kg} / \mathrm{d}$ & $\begin{array}{l}\text { - Cit: increase of } 448 \pm 92 \% \text { (from } 39 \pm 4 \text { to } 225 \pm 44 \text { ) } \\
\text { - Arg: increase of } 92 \pm 57 \% \text { (from } 134 \pm 33 \text { to } 247 \pm 62 \text { ) } \\
\text { - Increase in urine and RBC Cit } \\
\text { - No change in urinary Arg, nor plasma urea, urinary urea } \\
\text { nitrogen excretion thus enhanced nitrogen balance }\end{array}$ & 33 \\
\hline $\begin{array}{l}\text { Double-blind randomized } \\
\text { placebo-controlled } \\
\text { cross over study }\end{array}$ & 20 healthy volunteers & $\begin{array}{l}\text { Cit : } 0.75,1.5 \text { and } 3 \mathrm{~g} \text { twice daily } \\
\text { Arg: immediate release (IR) } 1 \mathrm{~g} \text { tid, sustained } \\
\text { release (SR) } 1.6 \text { twice daily for } 1 \text { week }\end{array}$ & $\begin{array}{l}\text { After load of } 3 \text { g Cit } \\
\text { - Cit : } \mathrm{T}_{\max }=0.7 \pm 0.1 \mathrm{~h}, \mathrm{C}_{\max }=846 \pm 45 \mu \mathrm{mol} / 1 \\
\text { - Arg : } \mathrm{T}_{\max }=1.4 \pm 0.1 \mathrm{~h}, \mathrm{C}_{\max }=149 \pm 42 \mu \mathrm{mol} / 1\end{array}$ & 35 \\
\hline $\begin{array}{l}\text { Simple-blind } \\
\text { cross over study }\end{array}$ & 8 healthy adult & $2,5,10$ or $15 \mathrm{~g}$ of $\mathrm{Cit}$ & $\begin{array}{l}\text { After ingestion of } 10 \mathrm{~g} \text { of Cit } \\
\text { - Cit } \mathrm{T}_{\max }=0.72 \pm 0.08 \mathrm{~h}, \mathrm{C}_{\max }=2756 \pm 70 \mu \mathrm{mol} / 1 \\
\text { - Arg } \mathrm{T}_{\max }=1.67 \pm 0.05 \mathrm{~h}, \mathrm{C}_{\max }=280 \pm 1043 \mu \mathrm{mol} / 1\end{array}$ & 32 \\
\hline $\begin{array}{l}\text { Cross-over pharmacokinetic } \\
\text { study }\end{array}$ & 7 normal volunteers & $\begin{array}{l}\text { Single equimolar oral dose of arg and cit } 3.8 \\
\mathrm{~g} / \mathrm{m}^{2} \text { body surface area }\end{array}$ & $\begin{array}{l}\text { After oral Cit load: } \\
\text { - Cit: increase } 40 \text { fold (from } 31 \pm 3 \text { to } 1275 \pm 95 \text { ) } \\
\text { - Arg: increase of } 227 \% \text { (from } 72 \pm 5 \text { to } 236 \pm 5 \text { ) } \\
\text { - Arg: AUC }=1440 \pm 196 \mu \mathrm{Mxhrs} \\
\text { After oral Arg load: } \\
\text { - Arg: increase of } 90 \% \text { (from } 107 \pm 19 \text { to } 229 \pm 33 \text { ) } \\
\text { - Arg : AUC }=476 \pm 259 \mu \mathrm{Mxhrs}\end{array}$ & 34 \\
\hline
\end{tabular}




\begin{tabular}{|c|c|c|c|c|}
\hline Study & Patients & Dosage $^{1}$ & Plasma concentration achieved, $\mu \mathrm{mol} / \mathrm{I}$ & Reference \\
\hline $\begin{array}{l}\text { Randomized placebo } \\
\text { controlled trial }\end{array}$ & $\begin{array}{l}40 \text { children undergoing surgery } \\
\text { to correct congenital heart } \\
\text { lesions }\end{array}$ & $\begin{array}{l}\text { Cit } 1.9 \mathrm{~g} / \mathrm{m}^{2} / \text { dose x } 5 \\
\text { Total dose of } 9.5 \mathrm{~g} / \mathrm{m}^{2}\end{array}$ & $\begin{array}{l}\text { 12h postoperative } \\
\text { Cit : } 37(18-83) \text { vs } 20 \pm(15-29) \text { (placebo) } \\
\text { Arg : } 36 \pm 24 \text { vs } 23 \pm 13 \\
57 \text { and } 85 \% \text { increases in mean plasma levels of Arg and } \\
\text { Cit, respectively }\end{array}$ & 57 \\
\hline Pilot phase II clinical trial & $\begin{array}{l}5 \text { sickle cell disease patients } \\
(\text { ages10-18) }\end{array}$ & 0.09 to $0.13 \mathrm{~g} / \mathrm{kg}$ twice daily for 4 weeks & Increase of $65 \%$ (from $77 \pm 9.1$ to $127 \pm 18$ ) in plasma Arg & 58 \\
\hline $\begin{array}{l}\text { Pharmacokinetic study after } \\
\text { watermelon ingestion }\end{array}$ & 6 healthy adults & $\begin{array}{l}3.3 \mathrm{~kg} \text { wet weight of red fruit of ripe } \\
\text { watermelon }\end{array}$ & $\begin{array}{l}\text { - Cit: increase from } 22 \mu \mathrm{mol} / \mathrm{L} \text { to } 593 \mu \mathrm{mol} / \mathrm{L} \text { (range } 386 \text { - } \\
\text { 1069) } 1 \mathrm{~h} \text { after ingestion } \\
\text { - Arg: increase from } 65 \mu \mathrm{mol} / \mathrm{L} \text { to } 199 \mu \mathrm{mol} / \mathrm{L} \text { (range } 128 \text { - } \\
\text { 251) } 2 \mathrm{~h} \text { after ingestion }\end{array}$ & 1 \\
\hline $\begin{array}{l}\text { Pharmacokinetic study after } \\
\text { watermelon ingestion }\end{array}$ & 23 healthy adults & $\begin{array}{l}780 \mathrm{~g} \text { (i.e. } 1 \mathrm{~g} \text { Cit), } 1560 \mathrm{~g} \text { (i.e. } 2 \mathrm{~g} \text { Cit) } \\
\text { watermelon juice for } 3 \text { weeks }\end{array}$ & $\begin{array}{l}\text { - Low ingestion of watermelon juice: } \\
\text { increase of } 12 \% \text { in plasma Arg } \\
\text { - High ingestion of watermelon juice: } \\
\text { increase of } 22 \% \text { in plasma } \mathrm{Arg}, 18 \% \text { in plasma Orn. }\end{array}$ & 31 \\
\hline
\end{tabular}

${ }^{\mathrm{I}}$ Citrulline or otherwise stated 